\title{
Selected miRNA levels are associated with IKZFI microdeletions in pediatric acute lymphoblastic leukemia
}

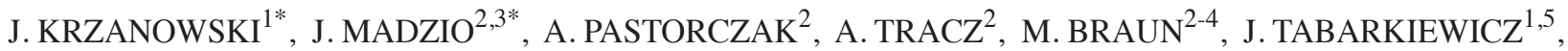 \\ A. PLUTA ${ }^{1}$, W. MŁYNARSKI ${ }^{2}$ and I. ZAWLIK ${ }^{1,6}$ \\ ${ }^{1}$ Centre for Innovative Research in Medical and Natural Sciences, University of Rzeszów, 35-959 Rzeszów; ${ }^{2}$ Department of \\ Pediatrics, Hematology, Oncology and Diabetology, Medical University of Łódź, 91-738 Łódź; ${ }^{3}$ Postgraduate School of \\ Molecular Medicine, Medical University of Warsaw, 02-091 Warsaw; ${ }^{4}$ Department of Pathology, Chair of Oncology, \\ Medical University of Łódź, 92-213 Łódź; Departments of ${ }^{5}$ Immunology and ${ }^{6}$ Genetics, Chair of \\ Molecular Medicine, Faculty of Medicine, University of Rzeszów, 35-959 Rzeszów, Poland
}

Received December 14, 2016; Accepted April 28, 2017

DOI: $10.3892 / \mathrm{ol} .2017 .6599$

\begin{abstract}
The clinical outcome of children with high-risk relapsed $\mathrm{B}$-cell precursor acute lymphoblastic leukemia (BCP-ALL) is poor. The present study assessed the utility and prognostic value of selected microRNA (miRNA/miR) in BCP-ALL. The changes in the expression levels of these miRNAs regarding known gene lesions affecting lymphoid development [early B-cell factor 1 (EBF1), ETS variant 6 (ETV6), IKAROS family zinc finger 1 (IKZF1), paired box 5 (PAX5), cyclin dependent kinase inhibitor $(C D K N) 2 A / C D K N 2 B$, retinoblastoma 1 ( $R B 1$ ), pseudoautosomal region $1(P A R 1)$, B-cell translocation gene 1 protein (BTG1)] were analyzed. The following miRNAs were analyzed: miR-24, miR-31, miR-128, miR-542, and miR-708. The present study focused on patients with deletions of the IKAROS transcriptional factor gene $I K Z F 1$, which is currently considered to be an independent negative prognostic factor for ALL outcome. It was demonstrated that the expression level of miR-128 was significantly lower in patients with $I K Z F 1$ deletion compared with patients without $I K Z F 1$ deletion. Additionally, low expression of miR-542 was associated with $C D K N 2 A / B$ and miR-31deletions, and low expression of miR-24 was associated with miR-31 deletion. Low expression of miR-31, miR-24, miR-708 and miR-128 was associated with $P A X 5$ deletion, high expression of miR-24 and miR-542 was associated with PARl deletion and high expression of miR-708
\end{abstract}

Correspondence to: Professor I. Zawlik, Centre for Innovative Research in Medical and Natural Sciences, University of Rzeszów, Warzywna 1A, 35-959 Rzeszów, Poland

E-mail: izazawlik@yahoo.com

*Contributed equally

Key words: pediatric acute lymphoblastic leukemia, microdeletions, transcriptional factors, $I K Z F 1$, microRNA was associated with ETV6 deletion. The expression of the selected miRNAs was not associated with deletions of BTG1, $E B F 1$ and $R B 1$. These data, by emphasizing the association of miRNAs expression level with microdeletions, may assist to elucidate ALL biology and contribute to future studies on the possible applications of the miRNA profile for diagnosis.

\section{Introduction}

Acute lymphoblastic leukemia (ALL) is the most common cancer malignancy and the leading cause of cancer-associated mortality in children (1). Assessment of the risk of relapse is crucial in modern treatment protocols, as relapses are the main cause of therapeutic failure in childhood ALL. Despite investigation of the clinical and cytogenetic predictors, there remains no sufficient marker enabling early identification of patients at high risk of relapse. Therefore, the molecular markers for risk assessment at the time of diagnosis and during the treatment course are urgently needed.

A particularly poor treatment outcome is observed in patients with B-cell precursor ALL (BCP-ALL) with $t(9 ; 22)$ (q34; 11 ) translocation, and in patients with breakpoint cluster region/ABL proto-oncogene 1, non-receptor tyrosine kinase $(B C R / A B L 1)$-like ALL subtypes (2). BCR/ABL1-like ALL exhibits a gene expression profile similar to $B C R / A B L 1$-positive ALL, but without $\mathrm{t}(9 ; 22)$ rearrangement (3). These leukemia subtypes are most commonly characterized by genetic abnormalities affecting the following pathways: Lymphoid development [early B-cell factor 1 (EBF1), ETS variant 6(ETV6), IKAROS family zinc finger (IKZF)1, LIM domain only 2 and paired box 5 (PAX5)]; signal transduction ( $A B L 1, A B L 2$, cytokine receptor-like factor 2, colony stimulating factor 1 receptor, erythropoietin receptor, interleukin 7 receptor, janus kinase 2, platelet derived growth factor receptor $\beta$ ); and tumor suppression and cell cycle regulation [cyclin dependent kinase inhibitor $(C D K N) 2 A / C D K N 2 B$, retinoblastoma 1 (RBI) and tumor protein 53] (4).

Microdeletions and point mutations of the aforementioned genes are considered important factors in lymphoblast differentiation and leukemia progression, but the final pathogenetic 
effect is controlled by post-transcriptional regulators (5-7). Small noncoding RNA molecules ( $\sim 22$ base pairs), referred to as microRNA ( $\mathrm{miRNA} / \mathrm{miR}$ ), are types of these regulators. miRNAs recognize a seed region in an mRNA sequence and destabilize mRNA by acting in a RNA-induced silencing complex, thereby inhibiting protein production (8). Evidence from previous studies indicates that miRNAs promote neoplastic transformation. In lymphoid cells, miRNA may serve a role in hematopoiesis, and in the development of leukemia by the suppression of tumor suppressor genes or stimulation of oncogenes $(9,10)$. Dysregulation of miRNA expression is observed in leukemic cells and is potentially linked to drug resistance and poor outcome $(11,12)$.

As aforementioned, miRNAs are involved in numerous processes at the transcription level, therefore their signature may reflect normal homeostatic processes as well as pathological changes and leukemogenic disturbance. This suggests that miRNAs are potential biomarkers for early leukemia detection.

The present study aimed to identify miRNAs whose expression level variations may be associated with known molecular defects in childhood ALL. To preselect the miRNAs, bioinformatics tools were used for in silico miRNA analysis, such as Mircancer.ecu.edu, miRWalk data base, miRTarBase, and microRNA.org (13). Based on target prediction, a set of potential miRNA markers: miR-24, miR-31, miR-128, miR-542 and miR-708were identified, and then their expression levels were evaluated in a cohort of children with ALL and their association with known prognostic genetic lesions and clinical features of ALL.

\section{Materials and methods}

miRNA profiles. For the analysis of the miRNA profiles, 5 miRNAs (miR-128, miR-542, miR-708, miR-24 and miR-31) were selected using bioinformatics tools and databases [miRCancer (14), miRWalk database (15), miRTarBase (16), microRNA.org (17)], and were selected using literature reviews (9-12). The mirSVR score was applied for ranking microRNA target sites by a downregulation score. The mirSVR is machine learning method based on regression modelling and was calculated based on seed-site pairing, site context, conservation and free-energy of the selected miRNAs (18).

Recruitment of patients. Children ( $<18$ years old) with B-cell lineage ALL (B-ALL) and T-cell lineage (T-ALL) were recruited from the Caucasian Polish population at the Department of Pediatrics, Oncology, Hematology and Diabetology, Medical University of Łódź (Łódź, Poland), and cooperating Centres of Pediatric Oncohematology in the cities of Bialystok, Bydgoszcz, Gdansk, Katowice, Kielce, Olsztyn, Poznan, Szczecin, and Zabrze (Poland). Ethics committee approval was obtained from the Institutional Review Board of the Medical University of Lodz (number, $\mathrm{RNN} / 226 / 11 / \mathrm{KE} / / \mathrm{KE}$ ). All patients were diagnosed between May 2004 and March 2014 and treated according to ALL-IC 2002 or 2009 protocols (19). Patients with a set of microdeletions, particularly $I K Z F 1$ defects, were preferentially enrolled into the study.
Minimal residual disease (MRD) monitoring. The bone marrow samples from patients with BCP-ALL were collected at three time points: At diagnosis and at 15 and 33 days of treatment protocol. The bone marrow samples from patients with BCP-ALL were analyzed with 8-color flow cytometry according to the protocols of the EuroFlow Consortium (20). These samples were processed according to the manufacturer's lyse and wash protocol (BD Biosciences, San Jose, CA, USA), with 1X FACS Lyse used for erythrocyte lysis (BD Biosciences) and analyzed with FACSCanto II flow cytometer (BD Biosciences). To ensure a sensitivity level of $\geq 10^{4}$, low-cellular samples were first subjected to erythrocyte lysis in $1 \mathrm{X}$ ammonium chloride solution (Pharm Lyse; BD Biosciences) in a bulk lysis protocol. Subsequently, the suspension of leukocytes was stained in a single 8-color tube with antibodies adequate for the blasts'phenotype at diagnosis. The reproducibility of the obtained results was ensured by complying with the standard operating procedures developed by EuroFlow based on daily quality assessment with fluorescent beads (Sphero Rainbow Calibration Particles; Spherotech, Lake Forest, IL, USA). For data analysis, FACSDiva 6.1 software (BD Biosciences) was used. Patients with number of blasts in peripheral blood $>1,000$ on the 8 th day following steroid administration were identified as steroid resistant.

DNA and RNA extraction. A total of 90 bone marrow samples were collected at the time of diagnosis (B-ALL, $n=66$; T-ALL, $\mathrm{n}=24$ ). For DNA and RNA isolation, $300 \mu \mathrm{l}$ bone marrow stored in TRIzol ${ }^{\circledR}$ reagent was used (Ambion; Thermo Fisher Scientific, Inc., Waltham, MA, USA). The isolation procedure was performed according to the manufacturer's protocol.

Reverse transcription and expression. The RNA samples, isolated from bone marrow, were used for miRNA expression analysis, namely reverse transcription (RT) of miRNA to complementary (c)DNA, amplification of cDNA and detection by TaqMan probes in quantitative polymerase chain reaction (qPCR). Each RT reaction was performed according to the manufacturer's protocol (TaqMan ${ }^{\circledR}$ MicroRNA Reverse Transcription kit; Thermo Fisher Scientific, Inc.) in $15 \mu 1$ [7 $\mu 1$ mix, $3 \mu 1$ primer (5X RT), $5 \mu 1$ RNA sample]. The sequences of Stem-Loop RT primer target sequences and miRNA assay IDs are described in Table I. The amount of RNA used for each reaction was $40 \mathrm{ng} /$ well (RNA concentration, $8 \mathrm{ng} / \mu \mathrm{l})$. RT-PCR was conducted under the following conditions: $30 \mathrm{~min}$ at $16^{\circ} \mathrm{C}, 30 \mathrm{~min}$ at $42^{\circ} \mathrm{C}, 5 \mathrm{~min} 85^{\circ} \mathrm{C}$ and hold at $4^{\circ} \mathrm{C}$.

Each qPCR reaction was performed in duplicate, in $18 \mu \mathrm{l}$ volumes (TaqMan ${ }^{\circledR}$ Gene Expression Master Mix $10 \mu 1$; 20X assay $\left.1 \mu \mathrm{l} ; \mathrm{H}_{2} \mathrm{O} 4 \mu \mathrm{l}\right)$ with $3 \mu \mathrm{l}$ of cDNA sample $(8 \mathrm{ng})$. TaqMan ${ }^{\circledR}$ microRNA assays (Thermo Fisher Scientific, Inc.) were used to analyze specific miRNAs (hsa-miR-31, TM:002279; hsa-miR-24-2, TM:002441; hsa-miR-542-5p, TM:002240; hsa-miR-708, TM:002341; hsa-miR-128a, TM:002216). For normalization of PCR, as an internal control, U6 snRNA (TM:001973) was used. PCRs were conducted in duplicate under the following protocol: $2 \mathrm{~min}$ at $50^{\circ} \mathrm{C}, 10 \mathrm{~min}$ at $95^{\circ} \mathrm{C}$, then 40 cycles of: $95^{\circ} \mathrm{C}$ for $30 \mathrm{sec}$ and $60^{\circ} \mathrm{C}$ for $1 \mathrm{~min}$.

The expression levels are presented as $2^{-\Delta \Delta \mathrm{Cq}}$ values, where $\Delta \mathrm{Cq}=\mathrm{Cq}$ (reference) $-\mathrm{Cq}$ (miRNA of interest), which produces 
Table I. miRNA assay identities and target sequences.

\begin{tabular}{lll}
\hline miRNA & Assay identity & \multicolumn{1}{c}{ Target sequence } \\
\hline hsa-miR-31 & TM:002279 & 5'-AGGCAAGAUGCUGGCAUAGCU-3' \\
hsa-miR-24-2 & TM:002441 & 5'-UGCCUACUGAGCUGAAACACAG-3' \\
hsa-miR-542-5p & TM:002240 & 5'-UCGGGGAUCAUCAUGUCACGAGA-3' \\
hsa-miR-708 & TM:002341 & 5'-AAGGAGCUUACAAUCUAGCUGGG-3' \\
hsa-miR-128A & TM:002216 & 5'-UCACAGUGAACCGGUCUCUUU-3' \\
U6 snRNA & TM:001973 & 5'-GTGCTCGCTTCGGCAGCACATATACTAAAATTGGAACGATACAGAGAAGATTA \\
& & GCATGGCCCCTGCGCAAGGATGACACGCAAATTCGTGAAGCGTTCCATATTTT-3'
\end{tabular}

miRNA/miR, microRNA.

Table II. Clinical characteristics of the study population.

\begin{tabular}{|c|c|c|c|c|}
\hline Variable & Total & T-ALL & B-ALL & P-value \\
\hline Total & 90 & 24 & 66 & \\
\hline Sex & & & & 0.16519 \\
\hline Male, n (\%) & $59(65.56)$ & $19(79.17)$ & $40(60.61)$ & \\
\hline Female, n (\%) & $31(34.44)$ & $5(20.83)$ & $26(39.39)$ & \\
\hline Age at diagnosis, years(IQR) & $8.36(3.62-12.88)$ & $8.87(3.22-13.05)$ & $8.05(3.79-12.73)$ & 0.98908 \\
\hline WBC, x10³/ $\mu 1$ (IQR) & $26.65(6.36-88.10)$ & $108.85(29.74-279.01)$ & $14.13(4.45-53.00)$ & 0.00008 \\
\hline MRD at day $15, \%$ (IQR) & $1.06(0.13-9.50)$ & $4.2(0.83-29.30)$ & $0.61(0.07-5.25)$ & 0.00740 \\
\hline Resistance to steroids, $\%$ & & & & 0.01456 \\
\hline Positive (IQR) & $14(15.55)$ & $8(33.33)$ & $6(9.09)$ & \\
\hline Negative (IQR) & $76(84.44)$ & $16(66.66)$ & $60(90.91)$ & \\
\hline
\end{tabular}

Nominal variables are presented as numbers with percentages in brackets and compared using the $\chi^{2}$ test, while continuous variables are presented as medians with interquartile ranges in brackets and compared using U Mann-Whitney test. Steroid resistance was defined as a peripheral blood blast count $>1,000$ in 8 th day of treatment. WBC, white blood cells; MRD, minimal residual diseases (measured as percentage of leukemic cells in bone marrow); T-ALL, T-cell lineage acute lymphoblastic leukemia; B-ALL, B-cell lineage acute lymphoblastic leukemia.

a higher value for higher miRNA expression, facilitating its use and interpretation as a biomarker (21).

Multiplex ligation-dependent probe amplification (MLPA). Copy number variations (CNVs) were identified by MLPA. Samples were screened for selected CNVs using P202-B1 and P335-B1 SALSA MLPA kits (MRC-Holland, Amsterdam, The Netherlands). These assays enable analysis of all exons of $C D K N 2 A / B$ and $I K Z F 1$ genes, and selected exons of $P A X 5$, BTG anti-proliferation factor 1 (BTG1), EBF1, ETV6, RB1, immunoglobulin heavy locus, IKZF2, IKZF3, metastasis associated 1 genes and the pseudoautosomal region 1 (PARl) region. The MLPA procedure was performed according to the manufacturer's protocols.

Statistical analysis. Statistical analysis was performed using Statistical 12.5PL software (StatSoft, Inc., Tulsa, OK, USA). The distribution of variables was tested with the Shapiro-Wilk test and Kolmogorov-Smirnov test with Lilliefors correction. Due to the non-normal distribution of all analyzed variables, non-parametric tests were used and the results are presented as medians followed by interquartile ranges (IQRs). $\mathrm{P}<0.05$ was considered to indicate a statistically significant difference. Categorical variables were compared using the $\chi^{2}$ test or Fisher's exact test. Continuous variables were compared using the U Mann-Whitney test to analyze differences between two groups and the Kruskal-Wallis along with post hoc (Dunn's) test to analyze differences between more than two groups. The $\mathrm{R}$ Spearman's correlation was used to analyze correlations between continuous variables.

\section{Results}

Study group characteristics. A total of 90 children were recruited, of which 24 (26.67\%) were diagnosed with T-ALL and $66(73.33 \%)$ were diagnosed with B-ALL (Table II). In the B-ALL group, 2 patients $(3.23 \%)$ exhibited a $B C R / A B L$ fusion, $1(1.67 \%)$ exhibited a mixed lineage leukemia $(M L L) / A F 4$ fusion and 11 (19.64\%) exhibited ETV6/runt related transcription factor 1 (RUNX1) fusions. BCR/ABL, MLL/AF4 and $E T V 6 / R U N X 1$ fusions were not identified among the patients with T-ALL.

Microdeletions were determined in $83(92.22 \%)$ patients (Table III). IKZF1 deletions and ETV6 deletions were 
Table III. Microdeletion profiles among included patients.

\begin{tabular}{|c|c|c|c|c|}
\hline Microdeletion locus & All & T-ALL & B-ALL & P-value \\
\hline$I K Z F 1$ & $28(33.73)$ & $2(10.52)$ & $26(40.62)$ & 0.01468 \\
\hline$C D K N 2 A / B$ & $51(61.44)$ & $13(68.42)$ & $38(59.37)$ & 0.65777 \\
\hline MIR31 & $18(23.07)$ & $3(18.75)$ & $15(24.19)$ & 0.75102 \\
\hline PAX5 & $16(20.00)$ & $2(11.76)$ & $14(22.22)$ & 0.50036 \\
\hline PARl & $19(26.76)$ & $3(23.07)$ & $16(27.58)$ & 1.00000 \\
\hline ETV6 & $17(24.28)$ & $0(0)$ & $17(29.82)$ & 0.02876 \\
\hline BTG1 & $5(7.14)$ & $0(0)$ & $5(8.77)$ & 0.57571 \\
\hline$E B F 1$ & $5(7.14)$ & $0(0)$ & $5(8.77)$ & 0.57571 \\
\hline$R B 1$ & $10(14.08)$ & $2(15.38)$ & $8(13.79)$ & 1.00000 \\
\hline
\end{tabular}

Categorical variables were compared using the $\chi^{2}$ test. All data presented at the number of deletions with percentages in brackets. IKZF1, IKAROS family zinc finger $1 ; C D K N 2 A / B$, cyclin dependent kinase inhibitor 2A/B; MIR31, microRNA 31; PAX5, paired box 5; PAR1, pseudoautosomal region 1; ETV6, ETS variant 6; $B T G 1$, B-cell translocation gene 1 protein; $E B F 1$, early B-cell factor $1 ; R B 1$, retinoblastoma 1.

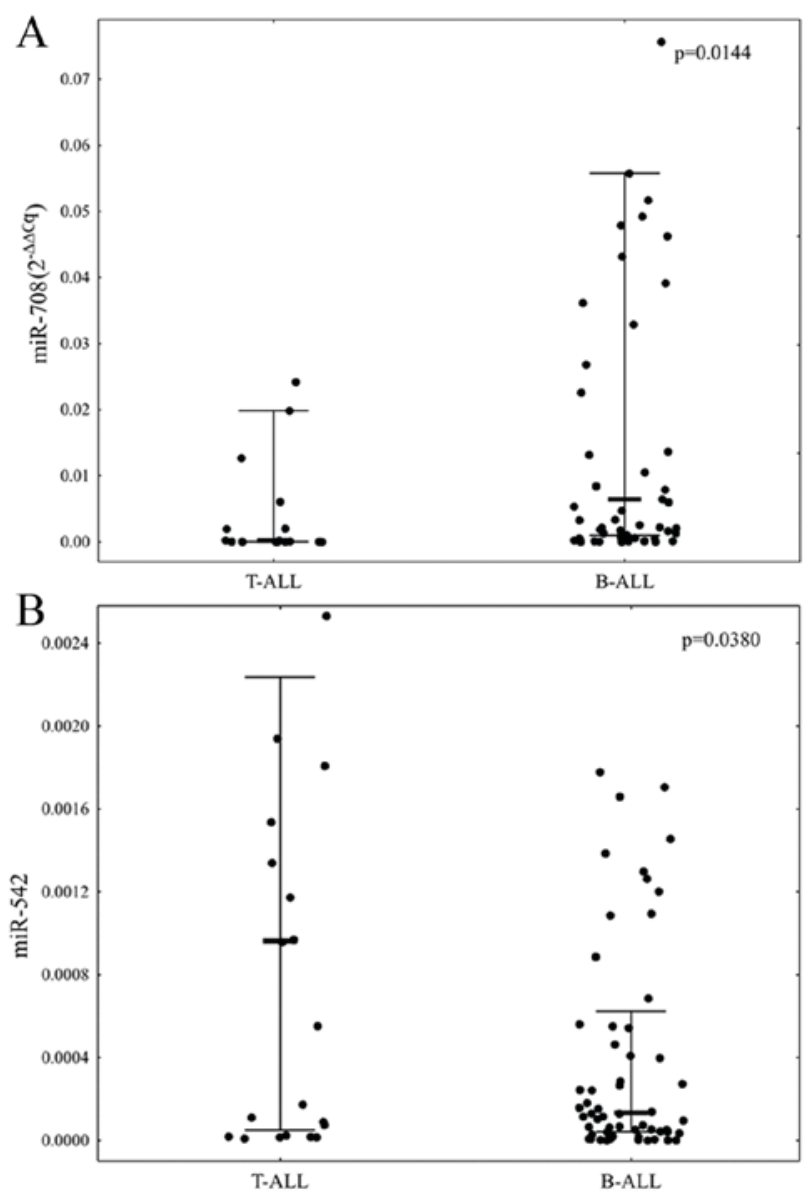

Figure 1. A comparison of the miR-708 and miR-542 expression levels between T-ALL and B-ALL patients. (A) P-value refers to the statistically significant difference in the expression level of miR-708 between patients with T-ALL and B-ALL. (B) P-value refers to the statistically significant differences in the expression level of miR-542 between patients with T-ALL and B-ALL. miRNA expression levels are presented as $2^{-\Delta \Delta \mathrm{Cq}}$ value. Bold line represents median, whiskers represent interquartile range and dots represent raw data. miRNA, microRNA; T-ALL, T-cell lineage acute lymphoblastic leukemia; B-ALL, B-cell lineage acute lymphoblastic leukemia.

more common in patients with B-ALL compared with patients with T-ALL $(40.63 \%$ vs. $10.53 \%, \mathrm{P}=0.0147$ and $24.28 \%$ vs. $0 \%, \mathrm{P}=0.029)$. No other significant differences in the microdeletion profiles between T-ALL and B-ALL were observed.

The expression levels of all selected miRNAs were measurable in $76(84.44 \%)$ of selected samples. A comparison of the expression levels of the selected miRNAs between T-ALL and B-ALL patients revealed that patients with B-ALL were characterized by significantly elevated level of miR-708 and decreased level of miR-542 ( $\mathrm{P}=0.0144$ and $\mathrm{P}=0.0380$, respectively; Fig. 1).

Due to the small number of patients with T-ALL with microdeletions, the expression levels of miRNAs with the microdeletion status were compared only within the group of patients with B-ALL. It was identified that the expression level of miR-128 was lower in patients with IKZFI deletions compared with patients without $I K Z F 1$ deletions $(\mathrm{P}=0.0265$, Fig. 2A). Deletions of $C D K N 2 A / B$ and MIR31 were associated with low expression of miR-542 in comparison with patients without deletions $(\mathrm{P}=0.0319$ and $\mathrm{P}=0.0021$, respectively; Fig. 2B). Patients with $P A X 5$ deletions exhibited significantly lower expression levels of miR-31, miR-24, miR-708 and miR-128 in comparison with patients without deletions of PAX5 (P=0.0368, 0.0115, 0.0312 and 0.0118 , respectively; Fig. 2C). Large deletions in the 9p21 chromosomal region, encompassing $C D K N 2 A, C D K N 2 B$ and MIR31 deletions, were also associated with low expression of miR-24 ( $\mathrm{P}=0.0067$; Fig. 3A). Deletions in the PAR1 region were associated with high expression levels of miR-24 and miR-542 ( $\mathrm{P}=0.0434$ and 0.0425 ; Fig. 3B and $\mathrm{C}$, respectively). Deletions of ETV6 were associated with a high expression of miR-708 $(\mathrm{P}=0.0341$, Fig. 3D). There was no association between the expression levels of selected miRNAs and deletions of BTG1, $E B F 1$, or $R B 1$ observed.

Correlation analyses revealed a negative correlation between age at diagnosis and $m i R-542\left(\mathrm{R}^{2}=-0.26\right.$, $\mathrm{P}=0.043)$, and between MRD at day 15 and $m i R-31(-0.32$, $\mathrm{P}=0.017)$ and $m i R-708(-0.32, \mathrm{P}=0.016)$ in patients with B-ALL (Table IV). There were no statistically significant associations with sex, WBC or resistance to steroid therapy observed. 

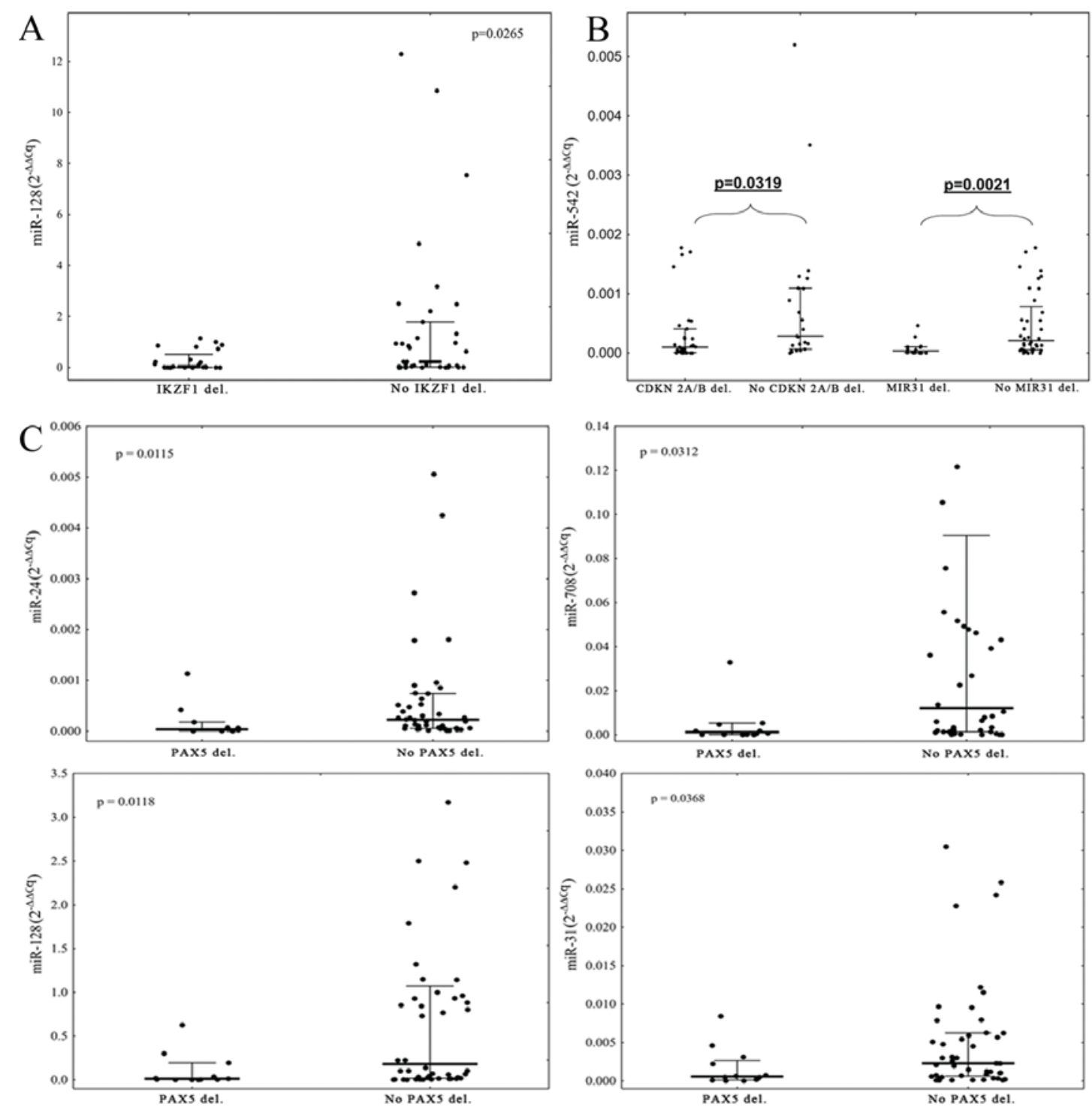

Figure 2. A comparison of the microRNAs expression levels with respect to $I K Z F 1, C D K N 2 A / B, M I R 31$ or $P A X 5$ deletion status. P-values refer to the statistically significant difference in the expression level of: (A) miR-128 with respect to IKZFI deletion status; (B) miR-542 with respect to $C D K N 2 A / B$ and $M I R 31$ deletion status; and (C) miRNAs expression level with respect to PAX5 deletion status in patients with B-ALL. Expression levels are presented as 2-4ACq value. Bold line represents median, whiskers represent interquartile range and dots represent raw data. miRNA, microRNA; B-ALL, B-cell lineage acute lymphoblastic leukemia.

\section{Discussion}

The data of the present study indicate that selected miRNAs: miR-128, miR-542, miR-708, miR-24 and miR-31, are associated with the ALL immunophenotype and microdeletion status of crucial genes affecting lymphoid development and cell cycle regulation.

Firstly, it was identified that the expression of miR-128 was lower in patients with $I K Z F 1$ deletions in comparison with patients without these deletions. IKZFI encodes Ikaros protein, which has a key role as a transcription factor in lymphocyte differentiation (22). Ikaros influences more than half of the known genes associated with hematopoiesis and early B-cell development (23). IKZFI deletions are associated with a poor outcome in high-risk groups of pediatric patients $(24,25)$. In a comparison between normal controls and patients with AML, an increased expression of miR-128 in patients with ALL has been suggested (26). Altered miR-128 expression may discriminate ALL from adult myeloid leukemia and normal bone marrow samples (27-30). Notably, Mi et al (27) revealed that the differential expression of miR-128 in acute leukemia is not a consequence of an altered genomic DNA copy number, and suggested that this miRNA is also under other types of DNA epigenetic regulation. The association between the lower expression of miR-128 and steroid resistance was not evaluated in the present study. In these and other previous studies, miR-128 expression did not correlate with other biological and clinical features $(28,31)$. The role of miR-128 insufficiency in the pathogenesis and response to treatment in patients with IKZFI-deletion ALL should be additionally examined with large-scale pediatric patients with ALL.

Lower miR-128 expression was detected in patients with deletion of another transcriptional factor gene, PAX5. Patients with $P A X 5$ deletions exhibited significantly lower expression levels of miR-31, miR-24 and miR-708 in comparison with patients without $P A X 5$ deletions. 
Table IV. Correlation analyses.

\begin{tabular}{llccrr}
\hline Variable & $m i R-31$ & $m i R-24$ & $m i R-708$ & $m i R-542$ & $m i R-128$ \\
\hline Age at diagnosis & -0.11 & -0.19 & -0.16 & $-\mathbf{- 0 . 2 6}^{\mathbf{c}}$ & -0.16 \\
WBC at diagnosis & -0.08 & 0.09 & -0.05 & -0.03 & 0.09 \\
MRD_15 & $\mathbf{- 0 . 3 2}$ & -0.11 & $\mathbf{- 0 . 3 2}$ & -0.11 & -0.19 \\
MRD_33 & -0.05 & 0.11 & 0.02 & -0.16 \\
\hline
\end{tabular}

Quantitative variables were compared using Spearmann's correlation analyses. We present all correlation coefficients bolded and followed by asterisks if significant. ${ }^{\mathrm{a}}{ }^{\mathrm{b}}$ and ${ }^{\mathrm{c}}$ stand for $\mathrm{P}=0.043, \mathrm{P}=0.016, \mathrm{P}=0.017$, respectively. WBC, white blood cells; MRD, minimal residual disease.
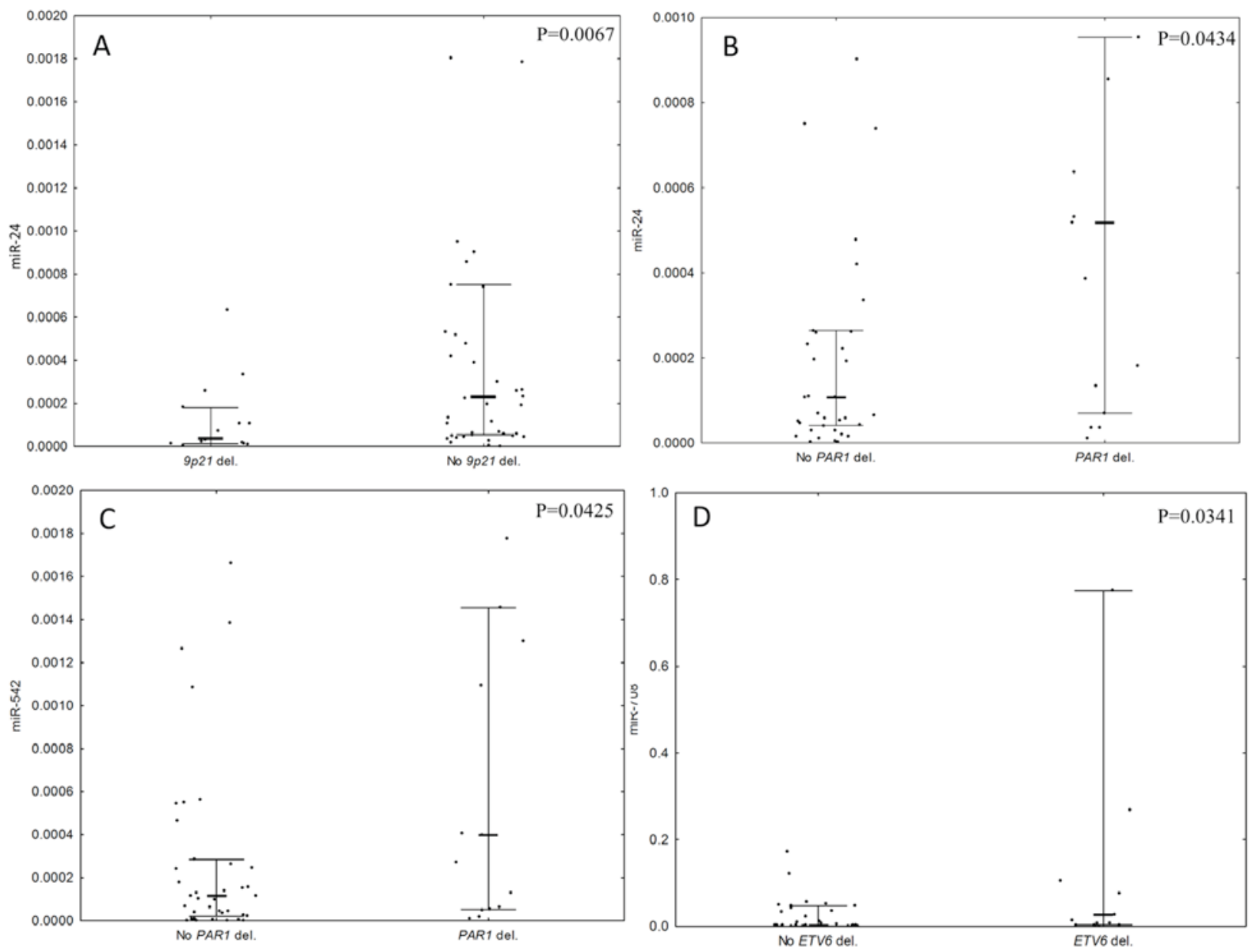

Figure 3. A comparison of the microRNA's expression levels with respect to 9p21, PAR1 and ETV6 deletion status. P-values refer to the statistically significant difference in the expression level of: (A) miR-24 with respect to 9p21 large deletion status; (B) miR-24 with respect to PAR1 deletion status and (C) miR-542 with respect to PAR1 deletion status in patients with B-ALL (D) miR-708 with respect to ETV6 deletion status. Expression levels are presented as 2-44Ca value. Bold line represents the median, whiskers represent interquartile range and dots represent raw data. miRNA, microRNA; B-ALL, B-cell lineage acute lymphoblastic leukemia; PAR1, pseudoautosomal region 1; ETV6, ETS variant 6.

Compared to patients with T-ALL, a high expression of miR-708 and a low expression of miR-542 was observed in patients with B-ALL. miR-708 was overexpressed in patients with ETV6 deletions, and this gene is involved in lymphoid development (32). These miRNAs were negatively correlated with MRD status at day 15 of the therapeutic protocol. Higher MRD was associated with lower miR-708. The investigation of miR-708 performed by de Oliveira et al (33) revealed lower miR-708 expression in normal bone marrow samples compared with ALL samples. In their study, miR-708 expression was not associated with clinical features, such as white blood cell level, bone marrow blast infiltration, steroid resistance, or central nervous system or testis involvement. Han et al (34) revealed a correlation between miR-708 and the response to glucocorticoid therapy, and suggested that low miR-708 expression was associated with higher risk of leukemogenesis or relapse. Higher miR-708 expression has been identified in patients with transcription factor ETV6-acute myeloid leukemia 1 protein, breakpoint cluster region-abelson tyrosine-protein kinase 1 (BCR-ABL1), 3-pre-B-cell leukemia transcription factor 1, 
hyperdiploid and 'B-other' ALL (B-cell ALL patients without aforementioned defects) compared with MLL-rearranged B-ALL and T-ALL cases $(12,35)$. In another study, Li et al (36) demonstrated that miR-708 was overexpressed in small groups of Chinese common precursor patients with B-ALL: Expression of miR-708 was higher in the high-risk group compared with the intermediate-risk group.

In the present study, deletions in the 9p21 chromosomal region $(C D K N 2 A$ and $C D K N 2 B, M I R 31)$ were associated with a lower expression of miR-542 in comparison with patients without deletions. miR-542 regulates the DNA repair/notch pathway in epithelial prostate cancer, and functions as a tumor suppressor in neuroblastoma $(37,38)$. This miRNA may positively regulate tumor protein 53 (p53) activity (39). The homozygous loss of the miR-31 gene is described in 9p instability in ALL (40). The 9p instability is detected in $19 \%$ of patients with ALL, and always includes the homozygous loss of $C D K N 2 A$ along with loss of $C D K N 2 B$, which are associated with $B C R / A B L 1$ and $I K Z F 1$ dysfunction (40-43). A lower expression of miR-542 is associated with a deletion of the $9 \mathrm{p}$ region. Schotte et al (12) demonstrated that miR-542 was 1 of 6 significantly upregulated miRNAs in T-ALL compared with normal thymocytes. Reduced expression of miR-542 and its role in B-ALL biology requires additional examination, as the current literature regarding miR-542 expression in ALL and lymphoproliferative diseases is limited. The present study also identified that deletions of MIR31were associated with a low miR-24 expression. miR-24 serves a role in the response to DNA damage, and may enhance apoptosis by targeting B-cell lymphoma $2(44,45)$. miR-24 potentially reduces cellular viability and induces apoptosis in combination with docetaxel (46). High expression of miR-24 also correlates with the response to DNA damage and apoptosis in cells treated with etoposide (47).

The present study observed altered miR-24 expression in patients with ALL with deletions in PAR1. PAR1 deletions are frequently observed in patients who are positive for IKZFI deletion (40). High expressions of miR-24 and miR-542 in patients who are positive for PAR1 deletion were detected. The expression level of miR-24 in patients with acute leukemia is higher compared with the healthy individuals, and is associated with shorter overall survival, high risk of relapse and poor survival (48).

Notably, the present study demonstrated that the lower expression of miR-31 and miR-708 was associated with a high MRD level and positive PAX5 mutation status. It should be emphasized that those two investigated miRNAs (miR-31 and miR-708) negatively influence the NF- $\kappa \mathrm{B}$ signaling pathway, which has a role in B-cell receptor activation (49). Aberrant B-cell receptor activation leads to a number of lymphoid malignancies (50). At present, targeted therapies are focused on the inhibition of BCR signaling $(51,52)$. miR-708 strongly represses $\mathrm{NF}-\kappa \mathrm{B}$ signaling in chronic lymphocytic leukemia (53). miR-31 in adult T-ALL negatively regulates the $\mathrm{NF}-\kappa \mathrm{B}$ pathway by targeting $\mathrm{NF}-\kappa \mathrm{B}$ inducing kinase (54). Based on this, it is hypothesized that the loss of activity of these miRNAs may serve a role in the pathogenesis of ALL, and in treatment failure.

Certain issues must be taken into consideration when interpreting the present data. One of the most conspicuous points is the mutation profile of the patients. The mutation rate in the study population is inconsistent with that of the general population, which is a consequence of the enrollment criteria. Patients with $I K Z F 1$ deletions were enrolled with priority as the present study was designed to focus on high-risk patients such as patients with $B C R / A B L 1$-like ALL. Another important issue is the underrepresentation of patients with T-ALL, and these patients were excluded from the majority of additional analyses. However, differences in the biological features between B-ALL and T-ALL were demonstrated. Data from another study suggesting that patients with B-ALL, in comparison to T-ALL, were characterized by lower white blood cell counts at diagnosis, lower MRD at day 15 of the therapeutic protocol and greater sensitivity to steroid treatment were also confirmed by the present study. Finally, it was not possible to elaborate the activity of all selected miRNAs in all the investigated samples. Despite this, the expression levels of at least 4 selected miRNAs were successfully measured in 84 patients $(93.33 \%)$. To the best of our knowledge, this is the first study estimating selected miRNA expression, genetic defects and clinical features in pediatric ALL subtypes. These data indicate that an aberrant miRNA pattern is associated with ALL types, and that microdeletions are commonly observed in high-risk patients with B-ALL.

As demonstrated in the present study, identifying the miRNA expression status in patients with ALL may be useful for elucidating the mechanisms of the disease. miRNAs may be used as molecular markers to assess risk of leukemia relapse, at the time of diagnosis, and to tailor specific therapies to the individual patient. Additional studies with larger cohorts are needed to examine the potential use of these miRNAs (miR-128, miR-542, miR-708, miR-24 and miR-31) as markers of genetic lesions.

\section{Acknowledgements}

The present study was supported by the National Science Centre, Poland (grant no. 2011/01/B/NZ4/03345). The study was performed within the project Centre for Innovative Research in Medical and Natural Sciences realized by the University of Rzeszow, and co-financed by Regional Operational Programme for the Podkarpackie Province for the years 2007-2013 (contract no. UDA-RPPK.01.03.00-18-004/12-00). Ms J. Madzio was supported by The National Science Centre (grant no. PRELUDIUM 2015/17/N/NZ5/00669). Dr M. Braun was supported by Polish Ministry of Science and Higher Education under the Diamond Grant Program (grant no. DI2012017042). Ms J. Madzio, Dr M. Braun and A.P. were also supported by National Centre of Research and Development (grant no. LIDER 031/635/1-5/13/NCBR/2014).

\section{References}

1. Ward E, DeSantis C, Robbins A, Kohler B and Jemal A: Childhood and adolescent cancer statistics, 2014. CA Cancer J Clin 64: 83-103, 2014

2. Schwab CJ, Chilton L, Morrison H, Jones L, Al-Shehhi H, Erhorn A, Russell LJ, Moorman AV and Harrison CJ: Genes commonly deleted in childhood B-cell precursor acute lymphoblastic leukemia: Association with cytogenetics and clinical features. Haematologica 98: 1081-1088, 2013 
3. Den Boer ML, van Slegtenhorst M, De Menezes RX, Cheok MH, Buijs-Gladdines JG, Peters ST, Van Zutven LJ, Beverloo HB, Van der Spek PJ, Escherich G, et al: A subtype of childhood acute lymphoblastic leukaemia with poor treatment outcome: A genome-wide classification study. Lancet Oncol 10: 125-134, 2009.

4. Mullighan CG: The genomic landscape of acute lymphoblastic leukemia in children and young adults. Hematology Am Soc Hematol Educ Program 2014: 174-180, 2014.

5. Figueroa ME, Chen SC, Andersson AK, Phillips LA, Li Y, Sotzen J, Kundu M, Downing JR, Melnick A and Mullighan CG: Integrated genetic and epigenetic analysis of childhood acute lymphoblastic leukemia. J Clin Invest 123: 3099-3111, 2013.

6. Yoshida T, Landhuis E, Dose M, Hazan I, Zhang J, Naito T, Jackson AF, Wu J, Perotti EA, Kaufmann C, et al: Transcriptional regulation of the Ikzf1 locus. Blood 122: 3149-3159, 2013.

7. Mavrakis KJ, Van Der Meulen J, Wolfe AL, Liu X, Mets E, Taghon T, Khan AA, Setty M, Rondou P, Vandenberghe P, et al: A cooperative microRNA-tumor suppressor gene network in acute T-cell lymphoblastic leukemia (T-ALL). Nat Genet 43 673-678, 2011

8. Bartel DP: MicroRNAs: Genomics, biogenesis, mechanism, and function. Cell 116: 281-297, 2004.

9. Garzon R, Calin GA and Croce CM: MicroRNAs in cancer. Annu Rev Med 60: 167-179, 2009.

10. Baer C, Claus R and Plass C: Genome-wide epigenetic regulation of miRNAs in cancer. Cancer Res 73: 473-477, 2013.

11. Calin GA and Croce CM: Investigation of microRNA alterations in leukemias and lymphomas. Methods Enzymol 427: 193-213, 2007.

12. Schotte D, De Menezes RX, Akbari Moqadam F, Khankahdani LM, Lange-Turenhout E, Chen C, Pieters R and Den Boer ML: MicroRNA characterize genetic diversity and drug resistance in pediatric acute lymphoblastic leukemia. Haematologica 96: 703-711, 2011.

13. Brennecke J, Stark A, Russell RB and Cohen SM: Principles of microRNA-target recognition. PLoS Biol 3: e85, 2005.

14. Xie B, Ding Q, Han H and Wu D: miRCancer: A microRNA-cancer association database constructed by text mining on literature. Bioinformatics 29: 638-644, 2013.

15. Dweep H, Sticht C, Pandey P and Gretz N: miRWalk-database: Prediction of possible miRNA binding sites by 'walking' the genes of three genomes. J Biomed Inform 44: 839-847, 2011.

16. Chou CH, Chang NW, Shrestha S, Hsu SD, Lin YL, Lee WH, Yang CD, Hong HC, Wei TY, Tu SJ, et al: miRTarBase 2016 : Updates to the experimentally validated miRNA-target interactions database. Nucleic Acids Res 44: D239-D247, 2016.

17. Betel D, Wilson M, Gabow A, Marks DS and Sander C: The microRNA.org resource: Targets and expression. Nucleic Acids Res 36: D149-D153, 2008.

18. Betel D, Koppal A, Agius P, Sander C and Leslie C: Comprehensive modeling of microRNA targets predicts functional non-conserved and non-canonical sites. Genome Biol 11: R90, 2010.

19. Campbell M, Castillo L, Janic D, Jazbec J, Kaiserova E, Konja J, Kovas G, Kowalczyk J and Soycan LY: ALL IC-BFM 2009 - A Randomized Trial of the I-BFM-SG for the Management of Childhood non-B Acute Lymphoblastic Leukemia; Final Version of Therapy Protocol from August-14-2009. http://tphd.org.tr/5th hematoloji_sempozyumu/Lebriz Yuksel_ALLIC BFM 2009.

20. van Dongen JJ, Lhermitte L, Böttcher S, Almeida J, van der Velden VH, Flores-Montero J, Rawstron A, Asnafi V, Lécrevisse Q, Lucio P, et al: EuroFlow antibody panels for standardized n-dimensional flow cytometric immunophenotyping of normal, reactive and malignant leukocytes. Leukemia 26 1908-1975, 2012

21. Livak KJ and Schmittgen TD: Analysis of relative gene expression data using real-time quantitative PCR and the 2-(Delta Delta C(T)) method. Methods 25: 402-408, 2001.

22. Schwickert TA, Tagoh H, Gültekin S, Dakic A, Axelsson E, Minnich M, Ebert A, Werner B, Roth M, Cimmino L, et al: Stage-specific control of early B cell development by the transcription factor Ikaros. Nat Immunol 15: 283-293, 2014.

23. Ferreirós-Vidal I, Carroll T, Taylor B, Terry A, Liang Z, Bruno L, Dharmalingam G, Khadayate S, Cobb BS, Smale ST, et al: Genome-wide identification of Ikaros targets elucidates its contribution to mouse B-cell lineage specification and pre-B-cell differentiation. Blood 121: 1769-1782,2013.

24. Mullighan CG, Su X, Zhang J, Radtke I, Phillips LA, Miller CB, Ma J, Liu W, Cheng C, Schulman BA, et al: Deletion of IKZF1 and prognosis in acute lymphoblastic leukemia. N Engl J Med 360: 470-480, 2009
25. Dörge P, Meissner B, Zimmermann M, Möricke A, Schrauder A, Bouquin JP, Schewe D, Harbott J, Teigler-Schlegel A, Ratei $\mathrm{R}$, et al: IKZF1 deletion is an independent predictor of outcome in pediatric acute lymphoblastic leukemia treated according to the ALL-BFM 2000 protocol. Haematologica 98: 428-432, 2013

26. Zhu YD, Wang L, Sun C, Fan L, Zhu DX, Fang C, Wang YH, Zou ZJ, Zhang SJ, Li JY and Xu W: Distinctive microRNA signature is associated with the diagnosis and prognosis of acute leukemia. Med Oncol 29: 2323-2331, 2012.

27. Mi S, Lu J, Sun M, Li Z, Zhang H, Neilly MB, Wang Y, Qian Z, Jin J, Zhang Y, et al: MicroRNA expression signatures accurately discriminate acute lymphoblastic leukemia from acute myeloid leukemia. Proc Natl Acad Sci USA 104: 19971-19976, 2007.

28. de Oliveira JC, Scrideli CA, Brassesco MS, Morales AG, Pezuk JA, Queiroz Rde P, Yunes JA, Brandalise SR and Tone LG: Differential miRNA expression in childhood acute lymphoblastic leukemia and association with clinical and biological features. Leuk Res 36: 293-298, 2012.

29. Zhang H, Luo XQ, Zhang P, Huang LB, Zheng YS, Wu J, Zhou H Qu LH, Xu L and Chen YQ: MicroRNA patterns associated with clinical prognostic parameters and CNS relapse prediction in pediatric acute leukemia. PLoS One 4: e7826, 2009.

30. Lu J, Getz G, Miska EA, Alvarez-Saavedra E, Lamb J, Peck D, Sweet-Cordero A, Ebert BL, Mak RH, Ferrando AA, et al: MicroRNA expression profiles classify human cancers. Nature 435: 834-838, 2005.

31. Wang Y, Li Z, He C, Wang D, Yuan X, Chen J and Jin J: MicroRNAs expression signatures are associated with lineage and survival in acute leukemias. Blood Cells Mol Dis 44: 191-197, 2010.

32. Wang LC, Swat W, Fujiwara Y, Davidson L, Visvader J, Kuo F, Alt FW, Gilliland DG, Golub TR and Orkin SH: The TEL/ETV6 gene is required specifically for hematopoiesis in the bone marrow. Genes Dev 12: 2392-2402, 1998.

33. de Oliveira JC, Scrideli CA, Brassesco MS, Yunes JA, Brandalise SR and Tone LG: MiR-708-5p is differentially expressed in childhood acute lymphoblastic leukemia but not strongly associated to clinical features. Pediatr Blood Cancer 62: 177-178, 2015.

34. Han BW, Feng DD, Li ZG, Luo XQ, Zhang H, Li XJ, Zhang XJ, Zheng LL, Zeng CW, Lin KY, et al: A set of miRNAs that involve in the pathways of drug resistance and leukemic stem-cell differentiation is associated with the risk of relapse and glucocorticoid response in childhood ALL. Hum Mol Genet 20: 4903-4915, 2011

35. Schotte D, Chau JC, Sylvester G, Liu G, Chen C, van der Velden VH, Broekhuis MJ, Peters TC, Pieters R and den Boer ML: Identification of new microRNA genes and aberrant microRNA profiles in childhood acute lymphoblastic leukemia. Leukemia 23: 313-322, 2009.

36. Li X, Li D, Zhuang Y, Shi Q, Wei W and Ju X: Overexpression of miR-708 and its targets in the childhood common precursor B-cell ALL. Pediatr Blood Cancer 60: 2060-2067, 2013.

37. Rane JK, Ylipää A, Adamson R, Mann VM, Simms MS, Collins AT, Visakorpi T, Nykter M and Maitland NJ: Construction of therapeutically relevant human prostate epithelial fate map by utilising miRNA and mRNA microarray expression data. Br J Cancer 113: 611-615, 2015.

38. Bray I, Tivnan A, Bryan K, Foley NH, Watters KM, Tracey L, Davidoff AM and Stallings RL: MicroRNA-542-5p as a novel tumor suppressor in neuroblastoma. Cancer Lett 303: 56-64, 2011.

39. Wang Y, Huang JW, Castella M, Huntsman DG and Taniguchi T: p53 is positively regulated by miR-542-3p. Cancer Res 74: 3218-3227, 2014

40. Usvasalo A,Ninomiya S,RätyR,HollménJ,Saarinen-PihkalaUM, Elonen E and Knuutila S: Focal 9p instability in hematologic neoplasias revealed by comparative genomic hybridization and single-nucleotide polymorphism microarray analyses. Genes. Chromosomes Cancer 49: 309-318, 2010.

41. Sherborne AL, Hosking FJ, Prasad RB, Kumar R, Koehler R, Vijayakrishnan J, Papaemmanuil E, Bartram CR, Stanulla M, Schrappe M, et al: Variation in CDKN2A at 9p21.3 influences childhood acute lymphoblastic leukemia risk. Nat Genet 42: 492-494, 2010

42. Olsson L, Albitar F, Castor A, Behrendtz M, Biloglav A, Paulsson $\mathrm{K}$ and Johansson B: Cooperative genetic changes in pediatric B-cell precursor acute lymphoblastic leukemia with deletions or mutations of IKZF1. Genes Chromosomes Cancer 54: 315-325, 2015. 
43. Braun M, Pastorczak A, Fendler W, Madzio J, Tomasik B, Taha J, Bielska M, Sedek L, Szczepanski T, Matysiak M, et al: Biallelic loss of CDKN2A is associated with poor response to treatment in pediatric acute lymphoblastic leukemia. Leuk Lymphoma 18 : 1162-1171, 2016

44. Lal A, Pan Y, Navarro F, Dykxhoorn DM, Moreau L, Meire E, Bentwich Z, Lieberman J and Chowdhury D: miR-24-mediated downregulation of $\mathrm{H} 2 \mathrm{AX}$ suppresses DNA repair in terminally differentiated blood cells. Nat Struct Mol Biol 16: 492-498, 2009

45. Srivastava N, Manvati S, Srivastava A, Pal R, Kalaiarasan P Chattopadhyay S, Gochhait S, Dua R and Bamezai RN: miR-24-2 controls H2AFX expression regardless of gene copy number alteration and induces apoptosis by targeting antiapoptotic gene BCL-2: A potential for therapeutic intervention. Breast Cancer Res 13: R39, 2011

46. Manvati S, Mangalhara KC, Kalaiarasan P, Srivastava N and Bamezai RN: miR-24-2 regulates genes in survival pathway and demonstrates potential in reducing cellular viability in combination with docetaxel. Gene 567: 217-224, 2015.

47. Brunner S, Herndler-Brandstetter D, Arnold CR, Wiegers GJ, Villunger A, Hackl M, Grillari J, Moreno-Villanueva M, Bürkle A and Grubeck-Loebenstein B: Upregulation of miR-24 is associated with a decreased DNA damage response upon etoposide treatment in highly differentiated CD8(+) T cells sensitizing them to apoptotic cell death. Aging Cell 11: 579-587, 2012

48. Organista-Nava J, Gómez-Gómez Y, Illades-Aguiar B, Del Carmen Alarcón-Romero L, Saavedra-Herrera MV, Rivera-Ramírez AB, Garzón-Barrientos VH and Leyva-Vázquez MA: High miR-24 expression is associated with risk of relapse and poor survival in acute leukemia. Oncol Rep 33: 1639-1649, 2015.
49. Talab F, Thompson V, Allen JC, Lin K and Slupsky JR: Characterisation of $\mathrm{B}$ cell receptor-induced NF- $\mathrm{B}$ activation in chronic lymphocytic leukaemia cells. Blood 116: 3765, 2015.

50. Niemann CU and Wiestner A: B-cell receptor signaling as a driver of lymphoma development and evolution. Semin Cancer Biol 23: 410-421, 2013.

51. Lannutti BJ, Meadows SA, Herman SE, Kashishian A, Steiner B, Johnson AJ, Byrd JC, Tyner JW, Loriaux MM, Deininger M, et al: CAL-101, a p110delta selective phosphatidylinositol-3-kinase inhibitor for the treatment of B-cell malignancies, inhibits PI3K signaling and cellular viability. Blood 117: 591-594, 2011.

52. Byrd JC, Furman RR, Coutre SE, Flinn IW, Burger JA, Blum KA, Grant B, Sharman JP, Coleman M, Wierda WG, et al: Targeting BTK with ibrutinib in relapsed chronic lymphocytic leukemia. N Engl J Med 369: 32-42, 2013.

53. Baer C, Oakes CC, Ruppert AS, Claus R, Kim-Wanner SZ, Mertens D, Zenz T, Stilgenbauer S, Byrd JC and Plass C: Epigenetic silencing of miR-708 enhances NF- $\mathrm{KB}$ signaling in chronic lymphocytic leukemia. Int J Cancer 137: 1352-1361, 2015.

54. Yamagishi M, Nakano K, Miyake A, Yamochi T, Kagami Y, Tsutsumi A, Matsuda Y, Sato-Otsubo A, Muto S, Utsunomiya A, et al: Polycomb-mediated loss of miR-31 activates NIK-dependent NF- $\mathrm{BB}$ pathway in adult $\mathrm{T}$ cell leukemia and other cancers. Cancer Cell 21: 121-135, 2012. 